\title{
Analytical Framework for Homeowner-Focused Computational Cost-Benefit Mitigation Decision Making
}

\author{
Fatemeh Orooji1* and Carol J. Friedland ${ }^{2}$ \\ ${ }^{1}$ School of Engineering and Applied Sciences, Western Kentucky University, Bowling Green, KY, United States, \\ ${ }^{2}$ Bert S. Turner Department of Construction Management, Louisiana State University, Baton Rouge, LA, United States
}

\section{OPEN ACCESS}

Edited by:

Yongkui Li,

Tongji University, China

Reviewed by:

Yanliang Niu,

Shijiazhuang Tiedao University, China Jamal Younes Omran,

Tishreen University, Syria

*Correspondence:

Fatemeh Oroo

fatemeh.orooji@wku.edu

Specialty section:

This article was submitted to

Construction Management,

a section of the journal

Frontiers in Built Environment

Received: 07 August 2020

Accepted: 14 October 2020

Published: 20 January 2021

Citation:

Orooji F and Friedland CJ (2021)

Analytical Framework

for Homeowner-Focused

Computational Cost-Benefit

Mitigation Decision Making.

Front. Built Environ. 6:592511.

doi: 10.3389/fbuil.2020.592511
As a result of increasing windstorm losses in the United States over the past 50 years, a variety of residential wind hazard mitigation strategies have been recommended. Wind hazard mitigation undoubtedly reduces windstorm losses; however, little customized information is available to support the economic decision-making process for individual stakeholders, especially at the consumer level. Therefore, there is a need for decision support tools to calculate, evaluate, and present the economic benefits of mitigation over variable decision-making time horizons for unique building characteristics in specific geographical locations. This paper presents a cost-benefit computational decision-making recommendation framework that evaluates and presents the cost effectiveness of mitigation, customized based on location, years of interest, and building characteristics. The decision-making framework consists of two cores. The userindependent core and user-dependent core which consists of eight steps, divided into four subprocesses: (1) data acquisition, (2) data evaluation, (3) cost-benefit calculation, and (4) results comparison and decision making. To demonstrate the framework, a wood-framed single-family home in light suburban terrain in Golden Meadow, Louisiana, is used as a case study, considering retrofit mitigation with a $\$ 15,000$ budget and a decision-making time horizon of 30 years. The case study provides six mitigation options, with cost ranging between approximately $\$ 2,000$ and $\$ 15,000$ and net benefit/cost ratios ranging from 2.4 to 13 . Once fully implemented in a decision making information tool, the developed mitigation recommendation framework will provide valuable information that can be used by home designers, builders, owners, and other stakeholders to better understand the economic facets of wind hazard mitigation, providing critical information as part of the overall decision-making process.

Keywords: decision making, cost-benefit, mitigation, analytical framework, wind hazards, wood-frame house

\section{INTRODUCTION}

Wind hazard risk reduction studies confirm that implementation of wind mitigation techniques reduces windstorm losses (e.g., Huang et al., 2001; Rosowsky and Ellingwood, 2002; Khanduri and Morrow, 2003; Peacock, 2003; Li and Ellingwood, 2006; Vickery et al., 2006; Heneka and Ruck, 2008; Pinelli et al., 2008; Pita et al., 2013; Torkian et al., 2013). In 2017, a cost-benefit analysis study commissioned by the Federal Emergency Management Agency (FEMA) found 
that at the national-level, every dollar investment in wind mitigation has a five dollar return on investment (MMC, 2017).

In spite of the obvious benefit of wind mitigation, investments in wind resilience are often not made by homeowners voluntarily (Chiew et al., 2020), in part due to uncertainty surrounding the potential costs and benefits of mitigation (Noori et al., 2018). Mitigation decision making is a challenge at many levels for homeowners. One of the basic challenges is that homeowners are often faced with many possible mitigation options. Evaluation of costs and benefits of each mitigation option supports and enhances consumer decision making of adaptation alternatives and facilitates comparison.

Cost-benefit analysis (CBA) is a method used for economic evaluation of risk reduction investment for future disaster events (Shreve and Kelman, 2014) and other types of decision making. CBA determines potential positive effects (i.e., loss avoided by implementing the mitigation) of mitigation actions and compares them to the cost of the action. CBA is concerned with efficiency (Godschalk et al., 2009) and is applied widely in literature to measure the economic benefits of various natural hazard or other mitigation methods (e.g., Smyth et al., 2004; FEMA, 2007, 2009; Pinelli et al., 2009; Li, 2012; Torkian et al., 2013). CBA is a decision support instrument for evaluating natural hazard risk reduction decisions and provides economic justification of the potential benefit of mitigation scenarios to improve natural hazard resilience. However, in spite of the utility of CBA methods, no tool or software is available to provide homeowners CBA data to facilitate their decision-making process.

Additionally, despite the usefulness of CBA in assessing the cost effectiveness of mitigation, the benefit of mitigation is not clear and not readily calculated by non-experts, as it requires evaluation of the risk of the hazard and the loss avoided through mitigation over the length of time the consumer is affected by the decision (Fuchs et al., 2007; Valcárcel et al., 2013). A prioritized and customized list of mitigation recommendations cannot be generally provided to homeowners at large; rather recommendations are unique based on building type and location. Therefore, without detailed modeling, these values are unknown, and consumers rely upon other decision factors, such as previous knowledge, risk perception, and social factors, among others. These shortcomings also reduce the ability of stakeholders, especially consumers, in their individual mitigation decision-making process.

This paper develops an analytical framework to support homeowner-focused computational mitigation recommendation decision making that evaluates the cost effectiveness of mitigation strategies using average annual loss (AAL) and develops customized mitigation recommendations based on location, years of interest, and building characteristics. The methodology relies upon calculation of the mitigation benefit, defined as the loss avoided through the implementation of mitigation; calculation of the cost of mitigation; evaluation of multiple mitigation scenarios along with consumer-input parameters; and presentation of the customized mitigation recommendation. In the calculations, inflation and discount rate are considered to evaluate the present value of future costs over the consumer decision-making time horizon. A typical, wood-framed, onestory, single-family home located in Golden Meadow, Louisiana, is used to demonstrate the functionality of the proposed framework. This paper fills the crucial gaps outlined through the development of the analytical framework that is needed to connect CBA methodologies and data with those making wind mitigation decisions and to calculate a custom, prioritized list of wind hazard mitigation recommendations based on building type and location in an automated process. Further, it expands upon the decision-making framework in and makes use of AAL libraries developed and published in toward the systematic development of a computational tool that will be developed at the consumer level to aid wind hazard mitigation decision making.

\section{CUSTOMIZED MITIGATION RECOMMENDATION FRAMEWORK}

The developed analytical framework consists of two cores. The user-independent core performs a single run of the intended application with fixed, unchanging input data. The input data for this core of the program are comprehensive AAL data in tabular format, mitigation cost data, and economic aspects of uncertainty including inflation and discount rate.

The user-dependent core of the program consists of eight steps, divided into four subprocesses: (1) data acquisition, (2) data evaluation, (3) cost-benefit calculation, and (4) results comparison and recommendations. The following sections describe each subprocess/step in detail. Figure $\mathbf{1}$ provides an overview of the proposed analytical framework for the decisionmaking tool.

\section{User-Independent Core}

One of the main datasets in the user-independent core is the AAL library. AAL libraries are defined as comprehensive tabulations of AAL data for multiple building types across a spatial domain subject to a range of wind speeds. Comprehensive AAL data are often implemented in catastrophe (cat) models, which are computational risk management tools that estimate future hazard-induced economic losses through linked hazard, exposure, and vulnerability modules (Clark, 2002; Grossi and Kunreuther, 2005; Christakis et al., 2008). These models are generally developed by private companies (e.g., Applied Insurance Research (AIR), Risk Management Solution (RMS, EQECAT) are used in the insurance industry (Chen et al., 2009; Hamid et al., 2011); many details of these proprietary models are not publicly available (Clark, 2002; Chen et al., 2009; Hamid et al., 2011). AAL is calculated by convolving the continuous loss curve, $L(v)$, and continuous probability density function for annual wind maxima, $f_{V}(v)$ (Pinelli et al., 2004; FEMA, 2012; Pita et al., 2013) (Eq. 1), which are both functions of wind speed, $v$. In this paper, the AAL tabular data developed by the authors and published in Orooji and Friedland (2020) were integrated.

$$
A A L=\int_{0}^{\infty} f_{V}(v) L(v) d v
$$

Based on the building characteristics reflected in AAL tables, mitigation categories and various options for each category are 


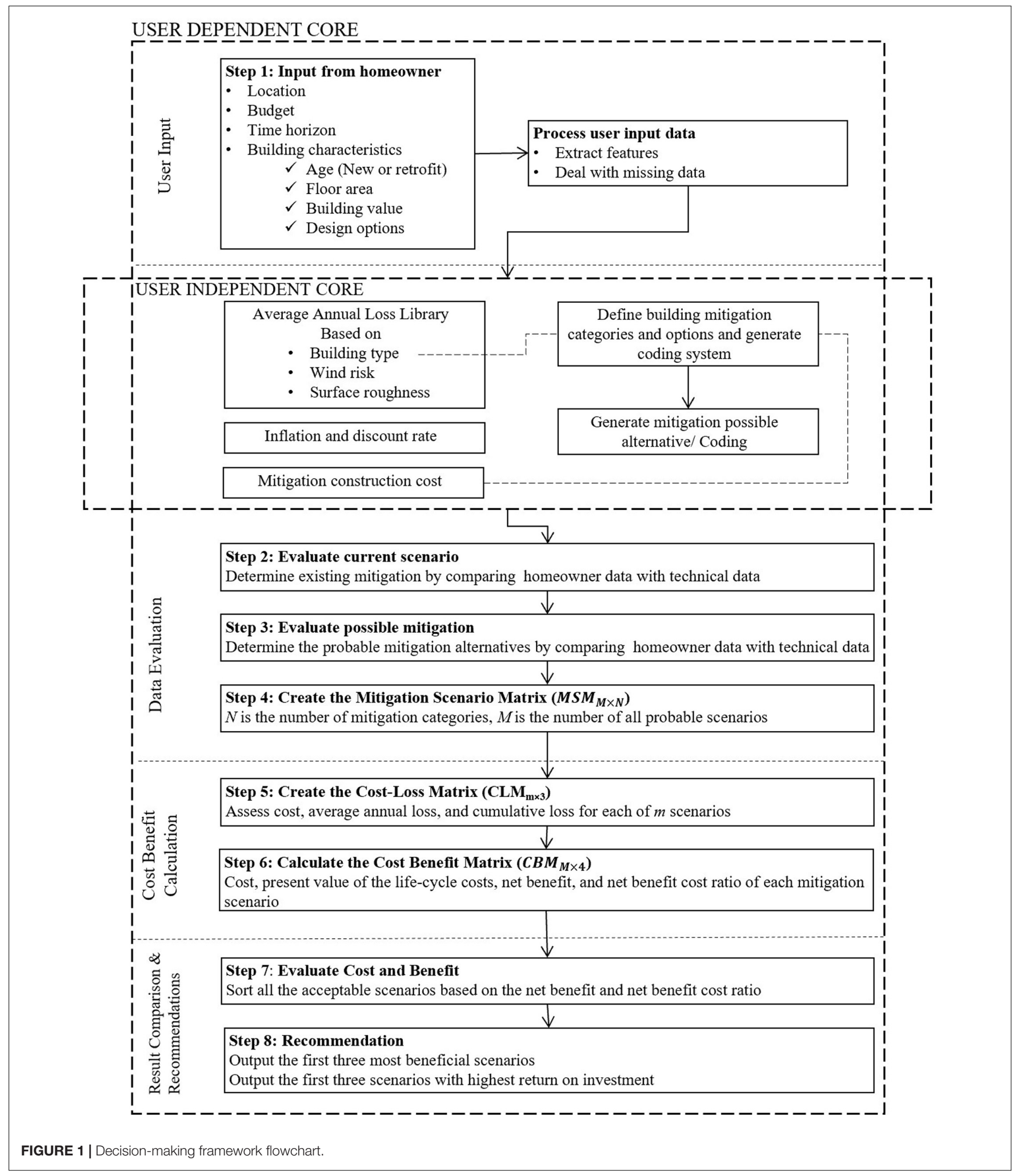

identified and numerically coded. Assuming that $N$ is the number of mitigation categories, each unique combination of building characteristics is designated by an $\mathrm{N}$-digit code.
Mitigation cost data and economic aspects of uncertainty including inflation and discount rate are also inserted as an input in the user-independent core. Cost data used 
in the research were collected from RSMeans Residential Cost Data (RSMeans, 2013). Variability in the cost data and uncertainty in economic aspects are not considered, although these topics remain important areas of future research.

\section{User-Dependent Core}

In the first subprocess-Data Acquisition, information is collected about building characteristics, location, and consumer demands. In this step, the homeowner provides information relevant to the building, including construction characteristics, value, size, and whether the building is new construction or retrofit, to allow evaluation of the current scenario in Step 2. The homeowner then provides location information which can be geolocated to determine the design wind speed contour and surface roughness length $\left(z_{0}\right)$. Existing datasets, such as those integrated into the Applied Technology Council (ATC) Wind Speed website ${ }^{1}$ and Hazus-Multi hazard (MH) Hurricane model, are used as default data to define the wind hazard and $z_{0}$, respectively. Homeowner requirements are also collected to define the available mitigation budget and the decisionmaking time horizon.

In the second subprocess-Data Evaluation, the current scenario is evaluated by mitigation categories and options in the user-independent core dataset to determine the building characteristics, determine possible mitigation actions, and create the Mitigation Scenario Matrix, which defines existing and possible mitigation options and identifies all possible mitigation combinations. Based on the building characteristics input in Step 1, some mitigation options may already be in place; therefore, the number and type of existing mitigation alternatives evaluated in Step 2 are based on the remaining mitigation categories and alternatives. Removing existing mitigation or choosing to weaken the building are not considered options; therefore, the remaining possible additional mitigation alternatives and categories are selected in Step 3. In Step 4, all possible combinations of existing and additional mitigation alternatives are evaluated, assuming $N$ is the number of mitigation categories and $M$ is the number of combination scenarios of existing and possible mitigation alternatives. Each scenario is populated in the Mitigation Scenario Matrix $\left(M S M_{M \times N}\right)$ and represented by an $N$-digit code which designates each unique combination of building characteristics.

In the third subprocess, Cost-Benefit Calculation, the cost and net benefit (NB) of each scenario are assessed through the construction of the Cost-Loss and Cost-Benefit Matrices in Steps 5 and 6, respectively. To evaluate the economic impact of each mitigation scenario, lifecycle cost assessment (LCCA) is used to determine the total present value of the life-cycle costs of each scenario due to wind damage, $P V_{m}$.

$P V_{m}$ considers monetary costs in terms of the initial cost of mitigation for scenario $m\left(C S_{m}\right)$ and the discounted present value (DPV) of $J$ associated ongoing and future costs for mitigation scenario $m$ (Eq. 2). The mitigation cost for scenario $m\left(C S_{m}\right)$

${ }^{1}$ http://windspeed.atcouncil.org/ calculated as the sum of each mitigation option for $N$ mitigation categories (Eq. 3), where $C_{i, n}$ is the cost of mitigation option $i$ for mitigation category $n$ that is considered in mitigation scenario $m$.

DPV represents the equivalent present value of future costs summed over $k$ years of the decision-making time horizon (Eq. 4), where $R_{A D}$ is the adjusted discount rate. The adjusted discounted rate, $\mathrm{R}_{\mathrm{AD}}$ (Eq. 5), relates the inflation, $R_{F}$, and discount, $R_{D}$, rates and allows consideration of the relationship between these rates. To evaluate the effectiveness of mitigation in reducing lifecycle costs, AAL must be considered annually as an ongoing cost category. AAL, defined as the average annual loss per year over a long period of time (Eq. 1) is often used to evaluate long-term risk from a probabilistic standpoint (Li, 2010; Torkian et al., 2013). To calculate the average cumulative loss, ACL, over the decision-making time horizon, the discounted present values of $A A L$ are summed over the decision-making time horizon of $K$ years (Eq. 6). Additional typical ongoing and future costs considered in LCCA are operation, maintenance, replacement, energy, and residual costs. These costs are conceptualized in the methodology for completeness; however, future cost for various wind hazard mitigation strategies is an understudied topic that merits future research to more accurately conduct LCCA.

$$
\begin{aligned}
& P V_{m}=C S_{m}+\left(\sum_{j=1}^{J} D P V_{j}\right)_{m} \\
& C S_{m}=\sum_{n=1}^{N} C_{i, n, m} \\
& D P V=A C L+\sum_{k=1}^{K} \frac{P V C_{k}}{\left(1+R_{A D}\right)^{k-1}} \\
& R_{A D}=\frac{1+R_{D}}{1+R_{F}}-1 \\
& A C L=\sum_{k=1}^{K} \frac{A A L}{\left(1+R_{A D}\right)^{k-1}}
\end{aligned}
$$

The Cost-Loss Matrix $\left(C L M_{M \times 3}\right.$; Eq. 7) contains the cost of mitigation and average loss of each scenario for all $M$ scenarios defined in Step 6. The first column of each row of the $C L M_{M \times 3}$ matrix represents the mitigation cost for scenario $m$. The second column of the $C L M_{M \times 3}$ matrix represents the average annual loss calculated using Eq. 1 and the third column represents the expected cumulative loss of the building, calculated using Equation 5.

$$
C L M=\left[\begin{array}{ccc}
C S_{1} & A A L_{1} & A C L_{1} \\
C S_{2} & A A L_{2} & A C L_{2} \\
\cdot & \cdot & \cdot \\
\cdot & \cdot & \cdot \\
\cdot & \cdot & \cdot \\
C S_{m} & A A L_{m} & A C L_{m}
\end{array}\right]
$$

The Cost-Benefit Matrix $\left(C B M_{M \times 4}\right)$ compares the cost and $\mathrm{NB}$ resulting from alternative mitigation scenarios, and also 
defines the overall relationship between the costs and benefits of each scenario. The NB of mitigation scenario $m, N B_{m}$, is evaluated as the difference between the present value of the current scenario PVcurrent and $P V_{m}$ (Equation 8). If scenario $m$ has a lower lifecycle cost, the $N B$ is positive, indicating an economic justification for implementing the mitigation. However, a negative $N B$ indicates that the current scenario is more appropriate over the decision-making time horizon than is scenario $m$. The cost effectiveness of mitigation scenario $m$ is calculated using the net benefit/cost ratio, $N B C R_{m}$, which is defined as the ratio of NB of the scenario to the initial cost of mitigation scenario, $C S_{m}$ (Equation 9).

$$
\begin{aligned}
& N B_{m}=P V_{\text {Current }}-P V_{m} \\
& N B C R_{m}=\frac{N B_{m}}{C S_{m}}
\end{aligned}
$$

The Cost-Benefit Matrix $\left(C B M_{M \times 4}\right)$ defines the cost of each mitigation scenario, present value of the life-cycle costs of each scenario, NB, and NBCR for each scenario (Eq. 10).

$$
C B M=\left[\begin{array}{cccc}
C S_{1} & P V_{1} & N B_{1} & N B C R_{1} \\
C S_{2} & P V_{2} & N B_{2} & N B C R_{2} \\
\cdot & \cdot & \cdot & \cdot \\
\cdot & \cdot & \cdot & \cdot \\
\cdot & \cdot & \cdot & \cdot \\
C S_{m} & P V_{m} & N B_{m} & N B C R_{m}
\end{array}\right]
$$

\section{Result Comparison and Recommendations}

In the final subprocess-Result Comparison and Decision Making, numerical data are evaluated to determine the most beneficial scenario(s), and the scenario(s) with the highest returns on investment are returned as output. Recommending the "best" scenario is not necessarily straightforward, as the needs/wants of the consumer may not necessarily align with the selection of the scenario with the highest NB or the highest NBCR. A scenario with the highest NB may not have the highest NBCR. NB indicates whether a mitigation scenario is actually worthwhile, and are sensitive to the overall magnitude of benefits. NBCRs reflect the magnitude of NBs relative to costs, and are a measure of the financial return of investment on mitigation. An NCBR greater than zero indicates a positive return on investment, and the scenario with the largest NCBR has a larger expected savings in losses over the life cycle, per dollar invested in mitigation.

Additionally, some scenarios with cost that is slightly higher than the budget input by the consumer may deliver a substantial benefit. Therefore, results within $5 \%$ of the maximum budget input in Step 1 are also considered acceptable outputs. The final recommendation consists of five optimal choices identified from the both the NB and NBCR calculations within 105\% of the consumer budget to allow the consumer to evaluate the output based on individual needs.

\section{CASE STUDY}

To illustrate the methodology, the results of the mitigation decision making framework for a single-family home built 10 years ago in Golden Meadow, Louisiana, are presented. The default ATC Wind Speed website (see footnote) was used to obtain site-specific wind speeds. Loss functions extracted from the Hazus-MH Hurricane Model for wood-framed, single-family, one-story buildings (WSF1) were used, which have been widely used for loss studies (e.g., Davidson et al., 2003; Jain et al., 2005; Rose et al., 2007; Amoroso and Fennell, 2008; Legg et al., 2010; Bjarnadottir et al., 2011; Pan, 2011). Within Hazus, WSF1 are categorized into 160 different types (FEMA, 2012). Table 1 provides the Hazus building ID (WBID) corresponding to each of the 160 model types by building characteristics.

As shown in Table 1, the five mitigation categories considered by Hazus are: roof shape, secondary water resistance (SWR), garage door configuration, shutter presence, roof-deck attachment, and roof-wall connection. The mitigation options available within Hazus for wind hazard mitigation are: (1) roof decks may be mitigated by increasing nail size (i.e., $6 \mathrm{~d}$ to $8 \mathrm{~d}$ ), decreasing nail spacing from 6 in./12 in. (edge/field nailing spacing) to 6 in./6 in., or a combination of the nail size and spacing; (2) roof-wall connections may be mitigated by using straps instead of toe-nail connections; (3) water intrusion resulting from loss of roof cover may be mitigated through the application of secondary water resistance, which covers the spaces between roof sheathing panels to prevent water penetration through the roof; (4) windows may be mitigated with the use of shutters; and (5) garage doors may be mitigated through the use of a reinforced door in compliance with the South Florida Building Code (SFBC 1994). Table 2 provides the five mitigation categories used within Hazus and the mitigation alternative coding developed for each category.

\section{Data Acquisition}

Figure 2 shows a 3D schematic of the case study building. Consumer input data relevant to the building and location collected in Step 1 are provided in Table 3. Based on the homeowner location input, wind speed data by mean recurrence interval are extracted from the ATC Wind Speed website (see text footnote 1) and two parameters of the Weibull probability function were calculated (Table 4) using the method presented in Orooji and Friedland (2017).

\section{Data Evaluation}

The current scenario and possible mitigation options are defined in Table 5 using the coding system provided in Table 2. For retrofit construction, the framework does not consider changing roof shape; therefore, the maximum number of mitigation scenarios is 80 . As mitigation alternatives already exist in the current scenario, the number of possible scenarios is further reduced as selecting weaker mitigation alternatives is not considered. The current scenario and the remaining possible mitigation alternatives by mitigation category are shown in Table 5. By evaluating the current mitigation scenario and the possible additional mitigation alternatives, $M S M_{M \times N}$ is 
TABLE 1 | Hazus-MH WSF1 Building ID (WBID) and corresponding building characteristics.

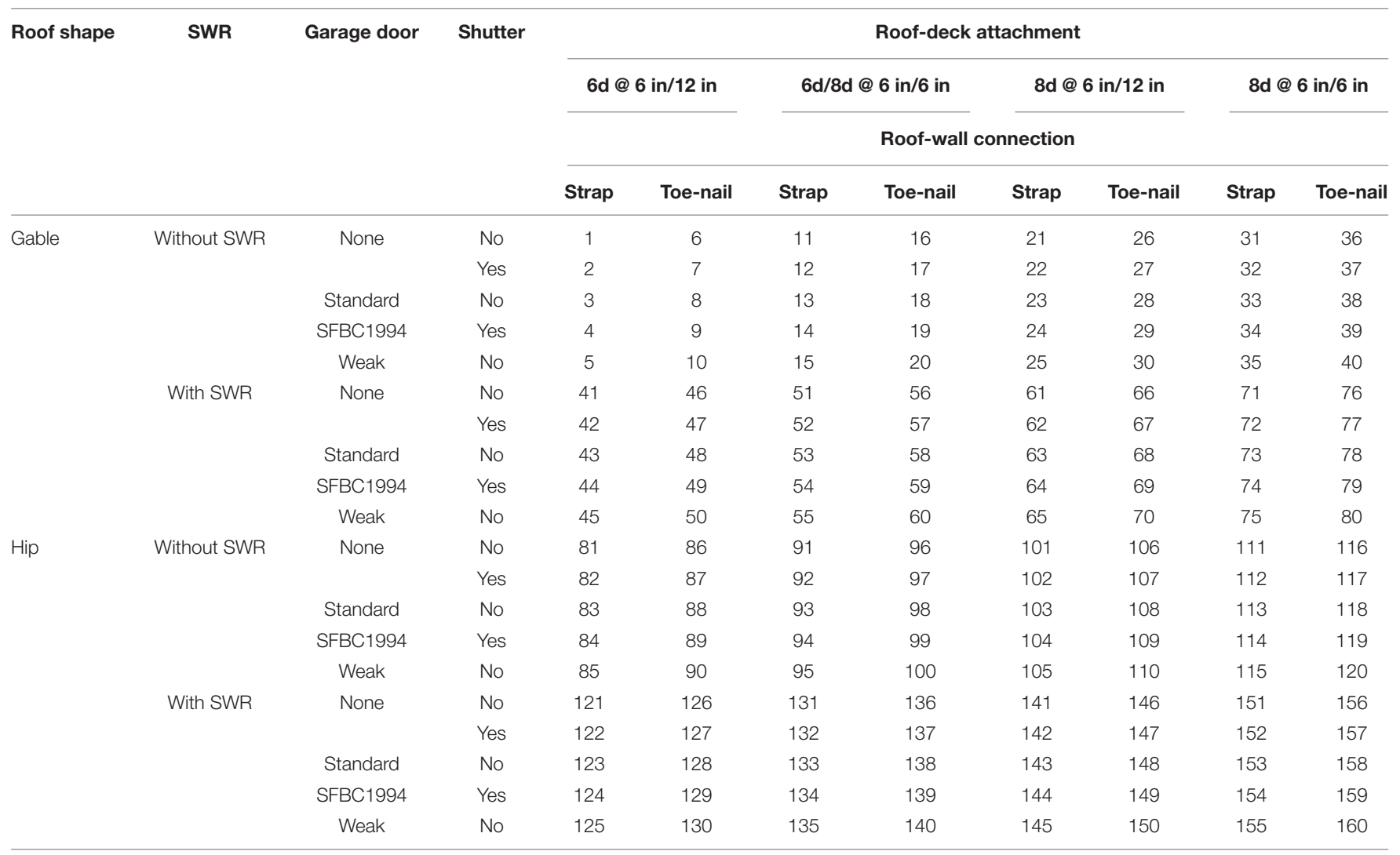

Number indicates Hazus-assigned WBID.

RDA, Roof Deck Attachment; RWC, Roof Wall Connection; SWR, Secondary Water Resistance.

TABLE 2 | Hazus-MH WSF1 mitigation categories and mitigation alternative coding.

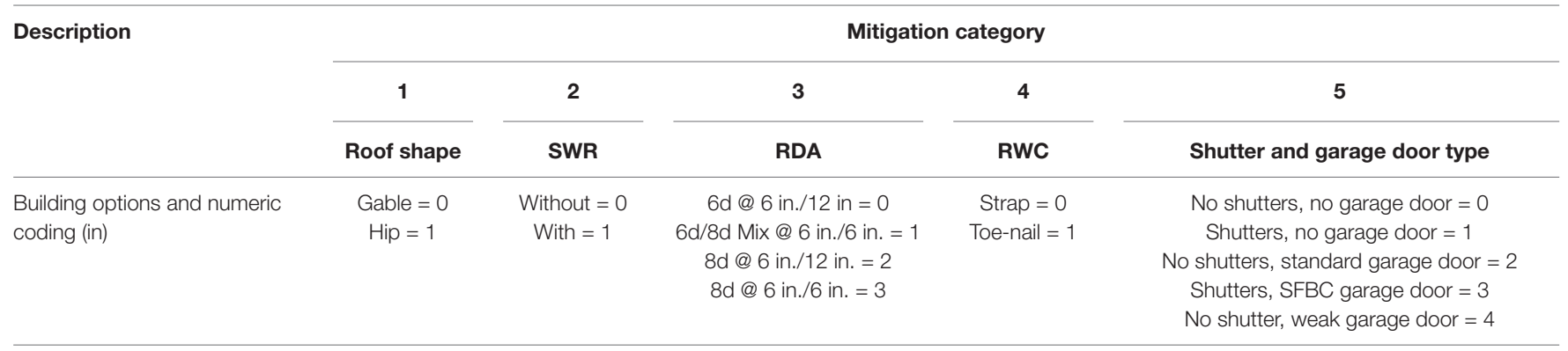

RDA, Roof-deck attachment; RWC, Roof-wall Connection; SWR, Secondary Water Resistance.

constructed, where $M=16$ (i.e., the unique number of mitigation alternative scenarios) and $N=5$.

\section{Cost-Benefit Calculation}

The initial mitigation investment cost data were collected from Orooji and Friedland (2017) and represent material, labor, equipment, and overhead costs. As discussed previously, future and ongoing maintenance, replacement, energy, and residual costs have not been developed specific to wind hazard mitigation techniques and therefore are not included in this analysis. Thus, the cost of each scenarios is limited to the initial mitigation investment and ongoing annual wind loss costs.
AAL for each mitigation scenario is calculated using Equation 1 , by convolving the continuous loss function, $L(v)$, extracted from Hazus from the WBID associated to the scenarios 1 through 16, and Weibull probability density function, $f_{V}(v)$. Average cumulative loss (ACL) for a homeowner time horizon of 30 years is calculated using Equation 6. The inflation rate $\left(R_{F}\right)$ and discounted rate $\left(R_{D}\right)$ are assumed to be constant for 30 years with rates of 4.3 and $8 \%$, respectively. Using the cost data, and AAL and ACL data for each of the mitigation scenarios, the cost-loss matrix $C L M_{16 \times 3}$ is created (Table 6). In the next step, the Cost-Benefit Matrix, $C B M_{16 \times 5}$, is created (Table 7). 


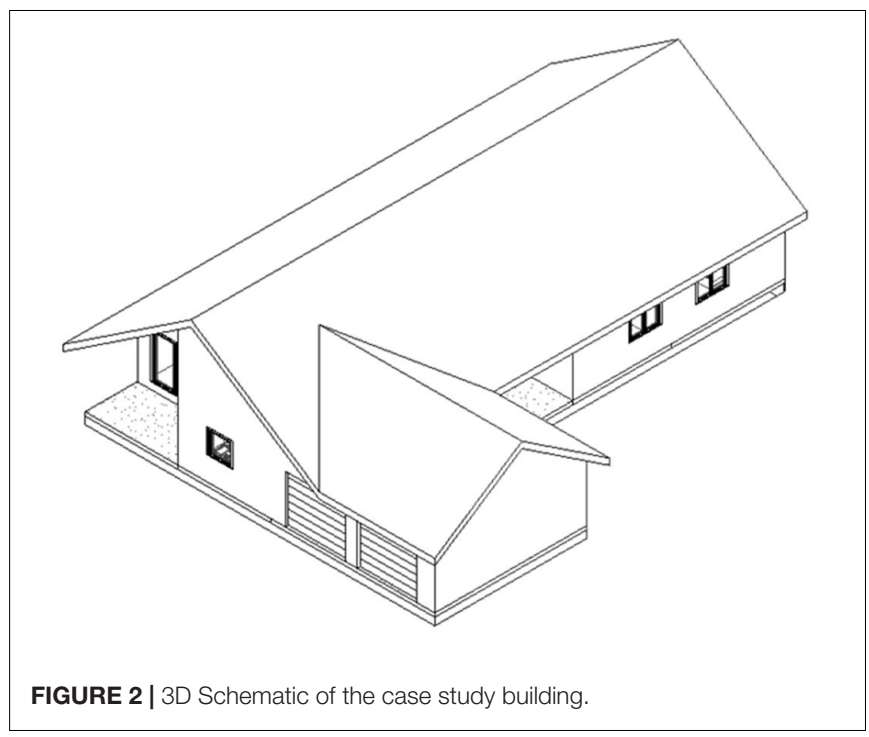

TABLE 3 | Input data collected in step 1 for case study example.

\begin{tabular}{lc}
\hline Data type & Input \\
\hline Location & Latitude 29.35 \\
& Longitude -90.24 \\
New construction or retrofit & Retrofit \\
Building value & $\$ 258,000$ \\
Floor area & 2,213 SF \\
Stories & 1 \\
Structure & Wood framing \\
Exterior & Siding \\
Primary roof shape & Gable \\
Roof slope & $6 / 12$ \\
SWR & No \\
Roof deck attachment & $6 d " / 12 "$ \\
Roof-wall connection & Toe-nail \\
Garage door & Standard \\
Shutter & No \\
Owner budget & $\$ 15,000$ \\
Decision-making time horizon & 30 years \\
ASCE 7 RC II wind speed contour & 160 mph \\
Terrain & Light suburban \\
Surface roughness, zo & $0.15 \mathrm{~m}$ \\
\hline &
\end{tabular}

\section{Result Comparison}

Given the CBM, NB, and NBCR are plotted for each mitigation scenario (Figure 3).
TABLE 5 | Possible mitigation alternatives.

\begin{tabular}{lccccc}
\hline & \multicolumn{5}{c}{ Mitigation category } \\
\cline { 2 - 6 } Mitigation & $\mathbf{1}$ & $\mathbf{2}$ & $\mathbf{3}$ & $\mathbf{4}$ & $\mathbf{5}$ \\
\hline Current mitigation & 0 & 0 & 0 & 1 & 2 \\
Possible mitigation actions & 0 & 0,1 & 0,1 & 0,1 & 2,3
\end{tabular}

\begin{tabular}{lcccccc}
\hline Mitigation scenario & & & & & & WBID \\
\hline 1 & 0 & 0 & 0 & 0 & 2 & 3 \\
2 & 0 & 0 & 0 & 0 & 3 & 4 \\
3 (Current) & 0 & 0 & 0 & 1 & 2 & 8 \\
4 & 0 & 0 & 0 & 1 & 3 & 9 \\
5 & 0 & 0 & 1 & 0 & 2 & 13 \\
6 & 0 & 0 & 1 & 0 & 3 & 14 \\
7 & 0 & 0 & 1 & 1 & 2 & 18 \\
8 & 0 & 0 & 1 & 1 & 3 & 19 \\
9 & 0 & 1 & 0 & 0 & 2 & 43 \\
10 & 0 & 1 & 0 & 0 & 3 & 44 \\
11 & 0 & 1 & 0 & 1 & 2 & 48 \\
12 & 0 & 1 & 0 & 1 & 3 & 49 \\
13 & 0 & 1 & 1 & 0 & 2 & 53 \\
14 & 0 & 1 & 1 & 0 & 3 & 54 \\
15 & 0 & 1 & 1 & 1 & 2 & 58 \\
16 & 0 & 1 & 1 & 1 & 3 & 59
\end{tabular}

Mitigation Categories: 1 = roof shape, $2=$ secondary water resistance at roof sheathing joints, 3 = roof deck attachment, 4 = roof wall connection, $5=$ shutter and garage door.

The $C B M_{M \times 4}$ is evaluated to remove the mitigation scenario(s) with cost exceeding budget, considering a margin of $105 \%$ of the budget input in Step 1 as the maximum budget ( $\$ 15,750$ for this case study). The cost of scenarios $14,6,16$, and 10 corresponding to WBID 54, 14, 59, and 44, respectively, exceed $105 \%$ of budget; therefore, they are removed from consideration. The remaining scenarios are sorted based on NB and NBCR to find the most beneficial scenario(s) and the scenario(s) with the highest return on investment (Table 8).

\section{Step 8: Mitigation Recommendations}

The five scenarios with the highest net benefit are selected based on the sorted scenario by benefit. Scenarios $8,2,12,13$, and 5 , corresponding to WBID $19,4,49,53$, and 13 , respectively, have the highest NBs within 105\% of the proposed budget. However, other scenarios deliver considerable benefit but at a lower cost; therefore, the five scenarios with highest net benefit-cost ratio are also selected. Scenarios 1, 4, 2, 5, and 13 corresponding to WBID 3, 9, 4, 13, and 53 have the highest return on investment

TABLE 4 | Peak gust wind speed $\mathrm{m} / \mathrm{s}$ (mph) by mean recurrence interval.

\begin{tabular}{|c|c|c|c|c|c|c|c|c|c|}
\hline & \multicolumn{6}{|c|}{ Return period, Year } & \multirow[b]{2}{*}{$1,700^{*}$} & \multirow[b]{2}{*}{ Weibull a } & \multirow[b]{2}{*}{ Weibull $u$} \\
\hline & 10 & 25 & 50 & 100 & $300^{*}$ & $700^{*}$ & & & \\
\hline
\end{tabular}

${ }^{*}$ ASCE 7-10 Risk Categories (RC) correspond to approximate MRI: I: 300 years, II: 700 years, III-IV: 1,700 years. 
TABLE 6 | Cost-loss matrix, CLM $24 \times 3$.

\begin{tabular}{lcccc}
\hline Mitigation scenario & WBID & $\mathbf{C S}_{\mathbf{m}}$ & $\mathbf{A A L}_{\mathbf{m}}$ & $\mathbf{A C L}_{\mathbf{m}}$ \\
\hline 1 & 3 & $\$ 1,700$ & $\$ 4,852$ & $\$ 91,848$ \\
2 & 4 & $\$ 7,700$ & $\$ 3,401$ & $\$ 64,393$ \\
3 (Current) & 8 & $\$ 0$ & $\$ 2,295$ & $\$ 43,439$ \\
4 & 9 & $\$ 6,000$ & $\$ 4,852$ & $\$ 91,848$ \\
5 & 13 & $\$ 10,775$ & $\$ 2,742$ & $\$ 51,912$ \\
6 & 14 & $\$ 16,775$ & $\$ 2,470$ & $\$ 46,765$ \\
7 & 18 & $\$ 9,075$ & $\$ 1,060$ & $\$ 20,076$ \\
8 & 19 & $\$ 15,075$ & $\$ 4,280$ & $\$ 81,036$ \\
9 & 43 & $\$ 10,887$ & $\$ 1,808$ & $\$ 34,235$ \\
10 & 44 & $\$ 16,887$ & $\$ 3,042$ & $\$ 57,591$ \\
11 & 48 & $\$ 9,187$ & $\$ 1,630$ & $\$ 30,867$ \\
12 & 49 & $\$ 15,187$ & $\$ 4,631$ & $\$ 87,665$ \\
13 & 53 & $\$ 11,795$ & $\$ 2,215$ & $\$ 41,926$ \\
14 & 54 & $\$ 17,795$ & $\$ 2,398$ & $\$ 45,390$ \\
15 & 58 & $\$ 10,096$ & $\$ 851$ & $\$ 16,104$ \\
16 & 59 & $\$ 16,096$ & $\$ 4,383$ & $\$ 82,977$ \\
\hline
\end{tabular}

TABLE 7 | Cost-benefit matrix, $C B M_{24 \times 3}$.

\begin{tabular}{lccccc}
\hline Mitigation scenario & WBID & $\mathbf{C S}_{\mathbf{m}}$ & $\mathbf{P V}_{\mathbf{m}}$ & $\mathbf{N B}_{\mathbf{m}}$ & $\mathbf{N B C R}_{\mathbf{m}}$ \\
\hline 1 & 3 & $\$ 1,700$ & $\$ 66,093$ & $\$ 25,755$ & 15.1 \\
2 & 4 & $\$ 7,700$ & $\$ 51,139$ & $\$ 40,709$ & 5.3 \\
3 (Current) & 8 & $\$ 0$ & $\$ 91,848$ & $\$ 0$ & $\mathrm{NA}$ \\
4 & 9 & $\$ 6,000$ & $\$ 57,912$ & $\$ 33,936$ & 5.7 \\
5 & 13 & $\$ 10,775$ & $\$ 57,540$ & $\$ 34,308$ & 3.2 \\
6 & 14 & $\$ 16,775$ & $\$ 36,851$ & $\$ 54,997$ & 3.3 \\
7 & 18 & $\$ 9,075$ & $\$ 90,111$ & $\$ 1,737$ & 0.2 \\
8 & 19 & $\$ 15,075$ & $\$ 49,310$ & $\$ 42,538$ & 2.8 \\
9 & 43 & $\$ 10,887$ & $\$ 68,478$ & $\$ 23,370$ & 2.1 \\
10 & 44 & $\$ 16,887$ & $\$ 47,754$ & $\$ 44,094$ & 2.6 \\
11 & 48 & $\$ 9,187$ & $\$ 96,852$ & $-\$ 5,004$ & -0.5 \\
12 & 49 & $\$ 15,187$ & $\$ 57,113$ & $\$ 34,735$ & 2.3 \\
13 & 53 & $\$ 11,795$ & $\$ 57,185$ & $\$ 34,664$ & 2.9 \\
14 & 54 & $\$ 17,795$ & $\$ 33,899$ & $\$ 57,949$ & 3.3 \\
15 & 58 & $\$ 10,096$ & $\$ 93,073$ & $-\$ 1,225$ & -0.1 \\
16 & 59 & $\$ 16,096$ & $\$ 46,999$ & $\$ 44,849$ & 2.8 \\
\hline & & & & &
\end{tabular}

(NBCR). These scenarios are considered as optimal solutions for the consumer (Table 9).

These 10 scenarios are provided to the consumer as the best mitigation scenarios, which the consumer can use as part of the overall decision-making process. Additionally, the consumer can be provided the full output from the Relative Cost-Benefit Matrix $\left(C B M_{m \times 4}\right)$ and sort scenarios based on cost, benefit, and NBCR to choose an optimal mitigation scenario based on consumer preference.

The case study mitigation scenario comparison (Table 8) resulted in nine potential mitigation scenarios that meet the user budget and have a positive net benefit (NB). The mitigation scenario disclosed four scenarios that exceeded $105 \%$ of the user budget, and two scenarios had a negative NB, resulting in six rejected scenarios. It is notable that the most beneficial mitigation

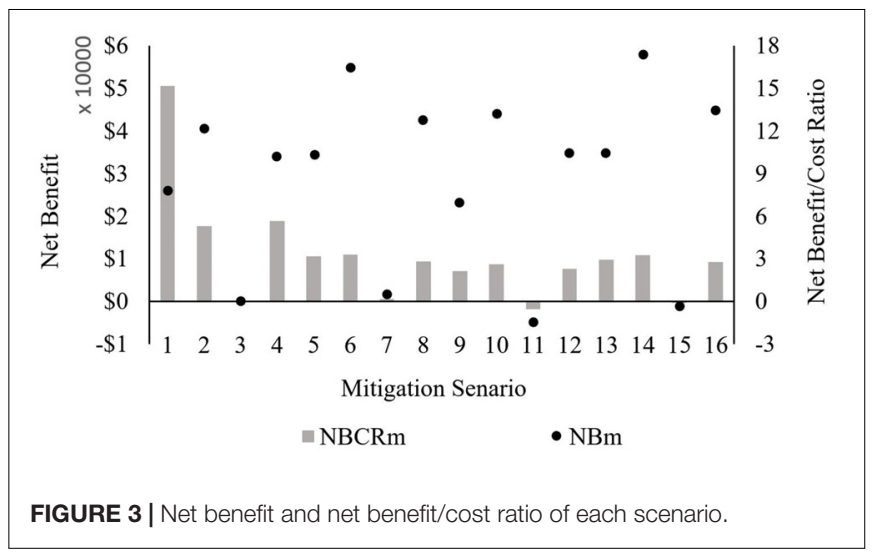

TABLE 8 | Mitigation scenario analysis results.

\begin{tabular}{|c|c|c|c|c|c|}
\hline Mitigation scenario & WBID & $\mathrm{CS}_{\mathrm{m}}$ & $\mathbf{P V}_{\mathrm{m}}$ & $\mathrm{NB}_{\mathrm{m}}$ & $\mathrm{NBCR}_{\mathrm{m}}$ \\
\hline 3 (Current) & 8 & $\$ 0$ & $\$ 91,848$ & $\$ 0$ & $N A$ \\
\hline \multicolumn{6}{|l|}{ Sorted by NB } \\
\hline 8 & 19 & $\$ 15,075^{a}$ & $\$ 49,310$ & $\$ 42,538$ & 2.82 \\
\hline 2 & 4 & $\$ 7,700$ & $\$ 51,139$ & $\$ 40,709$ & 5.29 \\
\hline 12 & 49 & $\$ 15,187^{a}$ & $\$ 57,113$ & $\$ 34,735$ & 2.29 \\
\hline 13 & 53 & $\$ 11,795$ & $\$ 57,185$ & $\$ 34,664$ & 2.94 \\
\hline 5 & 13 & $\$ 10,775$ & $\$ 57,540$ & $\$ 34,308$ & 3.18 \\
\hline 4 & 9 & $\$ 6,000$ & $\$ 57,912$ & $\$ 33,936$ & 5.66 \\
\hline 1 & 3 & $\$ 1,700$ & $\$ 66,093$ & $\$ 25,755$ & 15.15 \\
\hline 9 & 43 & $\$ 10,887$ & $\$ 68,478$ & $\$ 23,370$ & 2.15 \\
\hline 7 & 18 & $\$ 9,075$ & $\$ 90,111$ & $\$ 1,737$ & 0.19 \\
\hline \multicolumn{6}{|l|}{ Sorted by NBCR } \\
\hline 1 & 3 & $\$ 1,700$ & $\$ 66,093$ & $\$ 25,755$ & 15.15 \\
\hline 4 & 9 & $\$ 6,000$ & $\$ 57,912$ & $\$ 33,936$ & 5.66 \\
\hline 2 & 4 & $\$ 7,700$ & $\$ 51,139$ & $\$ 40,709$ & 5.29 \\
\hline 5 & 13 & $\$ 10,775$ & $\$ 57,540$ & $\$ 34,308$ & 3.18 \\
\hline 13 & 53 & $\$ 11,795$ & $\$ 57,185$ & $\$ 34,664$ & 2.94 \\
\hline 8 & 19 & $\$ 15,075^{a}$ & $\$ 49,310$ & $\$ 42,538$ & 2.82 \\
\hline 12 & 49 & $\$ 15,187^{a}$ & $\$ 57,113$ & $\$ 34,735$ & 2.29 \\
\hline 9 & 43 & $\$ 10,887$ & $\$ 68,478$ & $\$ 23,370$ & 2.15 \\
\hline 7 & 18 & $\$ 9,075$ & $\$ 90,111$ & $\$ 1,737$ & 0.19 \\
\hline \multicolumn{6}{|c|}{ Rejected mitigation scenarios } \\
\hline 14 & 54 & $\$ 17,795^{\mathrm{b}}$ & $\$ 33,899$ & $\$ 57,949$ & 3.26 \\
\hline 6 & 14 & $\$ 16,775^{\mathrm{b}}$ & $\$ 36,851$ & $\$ 54,997$ & 3.28 \\
\hline 16 & 59 & $\$ 16,096^{b}$ & $\$ 46,999$ & $\$ 44,849$ & 2.79 \\
\hline 10 & 44 & $\$ 16,887^{b}$ & $\$ 47,754$ & $\$ 44,094$ & 2.61 \\
\hline 15 & 58 & $\$ 10,096$ & $\$ 93,073$ & $-\$ 1,225$ & $-0.12^{c}$ \\
\hline 11 & 48 & $\$ 9,187$ & $\$ 96,852$ & $-\$ 5,004$ & $-0.54^{c}$ \\
\hline
\end{tabular}

${ }^{a}$ Cost exceeds budget but is less than $105 \%$ of budget.

${ }^{b}$ Cost exceeds $105 \%$ of budget.

${ }^{c} \mathrm{NBCR}$ is less than 0.0 .

scenario (Scenario 14) exceeded the user budget by nearly $\$ 2,700$ and was rejected.

In addition, Scenarios 1, 2, and 4 required a construction budget of $\$ 7,700$ or less and delivered $\mathrm{NB}$ ranging between $\$ 25,755$ and $\$ 40,709$. Four of the acceptable scenarios included upgrading roof to deck attachment through adding $8 \mathrm{~d}$ nails at 12 inches on center spacing to existing field nailing, which requires 
TABLE 9 | Optimal mitigation scenarios output to consumer for case study building.

\begin{tabular}{|c|c|c|c|c|}
\hline Mitigation actions & $\begin{array}{l}\text { Construction } \\
\text { cost }\end{array}$ & $\begin{array}{l}\text { Life cycle cost of } \\
\text { the scenario }\end{array}$ & Net benefit & $\begin{array}{l}\text { Net benefit/ } \\
\text { cost ratio }\end{array}$ \\
\hline $\begin{array}{l}\text { Add } 8 d \text { nails at } 12 \text { " on center to existing field nailing (requires replacement of roof cover and } \\
\text { may be more economical if done in conjunction with needed roof replacement) } \\
\text { Install rated shutters over windows and reinforce garage doors }\end{array}$ & $\$ 15,075$ & $\$ 49,310$ & $\$ 42,538$ & 2.82 \\
\hline $\begin{array}{l}\text { Replace toe-nail roof-wall connections with rated strap connections (requires the top } 4 \text { inches } \\
\text { of sheetrock to be removed and reinstalled) } \\
\text { Install rated shutters over windows and reinforce garage doors }\end{array}$ & $\$ 7,700$ & $\$ 51,139$ & $\$ 40,709$ & 5.29 \\
\hline $\begin{array}{l}\text { Add secondary water resistance (requires replacement of roof cover and may be more } \\
\text { economical if done in conjunction with needed roof replacement) } \\
\text { Install rated shutters over windows and reinforce garage doors }\end{array}$ & $\$ 15,187$ & $\$ 57,113$ & $\$ 34,735$ & 2.29 \\
\hline $\begin{array}{l}\text { Add } 8 d \text { nails at } 12 \text { " on center to existing field nailing and add secondary water resistance } \\
\text { (requires replacement of roof cover and may be more economical if done in conjunction with } \\
\text { needed roof replacement) } \\
\text { Replace toe-nail roof-wall connections with rated strap connections (requires the top } 4 \text { inches } \\
\text { of sheetrock to be removed and reinstalled) }\end{array}$ & $\$ 11,795$ & $\$ 57,185$ & $\$ 34,664$ & 2.94 \\
\hline $\begin{array}{l}\text { Add } 8 d \text { nails at } 12 \text { " on center to existing field nailing (requires replacement of roof cover and } \\
\text { may be more economical if done in conjunction with needed roof replacement) } \\
\text { Replace toe-nail roof-wall connections with rated strap connections (requires the top } 4 \text { inches } \\
\text { of sheetrock to be removed and reinstalled) }\end{array}$ & $\$ 10,775$ & $\$ 57,540$ & $\$ 34,308$ & 3.18 \\
\hline $\begin{array}{l}\text { Replace toe-nail roof-wall connections with rated strap connections (requires the top } 4 \text { inches } \\
\text { of sheetrock to be removed and reinstalled) }\end{array}$ & $\$ 1,700$ & $\$ 66,093$ & $\$ 25,755$ & 15.15 \\
\hline Install rated shutters over windows and reinforce garage doors & $\$ 6,000$ & $\$ 57,912$ & $\$ 33,936$ & 5.66 \\
\hline
\end{tabular}

replacement of roof cover. Therefore, it may be more economical if done in conjunction with needed roof replacement, which was noted in the homeowner output (Table 9). Four scenarios included improving roof-to-wall connection by replacing toe-nail connections with rated strap connections. This mitigation action requires removing and reinstalling the top 4 inches of sheetrock, which also was noted in the homeowner output (Table 9). It is noteworthy that the first three scenarios with the highest $\mathrm{NB}$, scenarios 19 and 4, recommended installing rated shutters over windows and reinforcing garage doors. Moreover, scenario 9 indicated that only installing rated shutters over windows and reinforcing garage doors results in $\mathrm{NB}$ of nearly $\$ 34,000$ and NBCR of 5.66 .

\section{Additional Assumptions, Limitations, and Future Work}

This section describes additional assumptions, limitations, and future work of the proposed analytical framework that merit discussion.

First, the study used direct economic loss functions extracted from the Hazus-MH Hurricane Model repository for woodframed, one-story, single-family homes. Therefore, it reflects the inherent limitations within the Hazus for building characteristics, mitigation options, and loss functions. Variability within the building types is not considered. Further, this research applied average annual loss only in terms of the mean loss. Variability of the mean and other statistical measures such as probable maximum loss and quantile losses are not considered. Extensive future work is needed to build enhanced loss functions that include wind loss uncertainty within the public domain.

In addition, initial cost data used in the research were obtained from Orooji and Friedland (2017) and reflect data obtained from a local builder's supply store, big box stores, and published component-level RSMeans housing-cost data (RSMeans, 2013). Therefore, variability in the cost data and uncertainty in economic aspects were not considered. This is another area that merits additional future research. Future and ongoing operation, maintenance, replacement, energy, and residual costs of wind mitigation options is another area that merits future research. For example, in installing shutters over windows, there are costs such as regular painting, cleaning, and planned replacement that should be considered to accurately evaluate different mitigation scenarios. Development of these cost data are an area of future work for the authors and others working on wind hazard loss reduction research.

This paper focused on developing an analytical framework which will eventually facilitate a wind hazard mitigation decision-making process for homeowners of single-story, woodframed residential buildings using cost-benefit analysis. The methodology will be expanded in the future to include additional residential construction types. Moreover, future work is needed that applies multi-criteria decision-making (MCDM) methods that consider an expanded set of criteria outside of direct economic loss.

The methodology presented in this paper was created to be adaptable to the input data associated with hazards, building types, loss, and cost data. Therefore, as improved data are developed, the methodology will accommodate their use and provide improved wind mitigation recommendations.

\section{SUMMARY AND CONCLUSION}

This paper presents an analytical framework that evaluates cost effectiveness, defined as net benefit and net benefit-cost 
ratio, of mitigation strategies to develop customized mitigation recommendations based on location, years of interest, and building construction characteristics. This framework builds on the overall objective described in Orooji and Friedland (2017) and integrates AAL libraries in Orooji and Friedland (2020). The present paper contributes to this growing body of work underpinning the development of a homeownerfocused computational mitigation recommendation decision making tool. The important contributions of this study are:

- An analytical framework was developed that consists of two cores; the user-independent core and user-dependent core which consists of eight steps, divided into four subprocesses: (1) data acquisition, (2) data evaluation, (3) cost-benefit calculation, and (4) results comparison and decision making.

- The proposed framework determines the current mitigation scenario, identifies all possible mitigation scenarios, and assigns a unique numerical code to each mitigation scenarios and generates mitigation scenario matrix, cost-loss matrix, and cost benefit matrix. Then generates customized mitigation solutions considering the cost, benefit, and NBCR of each mitigation scenario.

- The results of this framework provide consumer-level guidance to assist the mitigation decision-making process customized based on location, decision-making time horizon, building characteristics, and budget.

\section{REFERENCES}

Amoroso, S. D., and Fennell, J. P. (2008). "A rational benefit/cost approach to evaluating structural mitigation for wind damage: learning "the hard way" and looking forward," in Proceedings of the Structures Congress 2008 (Vancouver: ASCE). doi: 10.1061/41016(314)249

Bjarnadottir, S., Li, Y., and Stewart, M. G. (2011). A probabilistic-based framework for impact and adaptation assessment of climate change on hurricane damage risks and costs. Struct. Saf. 33, 173-185. doi: 10.1016/j.strusafe.2011.02.003

Chen, S.-C., Chen, M., Zhao, N., Hamid, S., Chatterjee, K., and Armella, M. (2009). Florida public hurricane loss model: research in multi-disciplinary system integration assisting government policy making. Gov. Inform. Q. 26, 285-294. doi: 10.1016/j.giq.2008.12.004

Chiew, E., Davidson, R. A., Trainor, J. E., Nozick, L. K., and Kruse, J. L. (2020). The impact of grants on homeowner decisions to retrofit to reduce hurricaneinduced wind and flood damage. Weather Clim. Soc. 12, 31-46. doi: 10.1175/ WCAS-D-18-0139.1

Christakis, M., Kobayashi, K., Scawthorn, C., and Porter, K. (2008). Open risk analysis software: data and methodologies. JSCE J. Comput. Civil Eng. 17, 1-12. doi: 10.2208/journalac2003.17.0_1

Clark, K. M. (2002). The use of computer modeling in estimating and managing future catastrophe losses. Geneva Pap. Risk Insur. Issues Pract. 27, 181-195. doi: 10.1111/1468-0440.00163

Davidson, R., Zhao, H., and Kumar, V. (2003). Quantitative model to forecast changes in hurricane vulnerability of regional building inventory. J. Infrastruct. Syst. 9, 55-64. doi: 10.1061/(ASCE)1076-034220039:2(55)

FEMA (2007). Using Benefit-Cost Review in Mitigation Planning. How-To Guide Number Five. Washington, DC: FEMA.

FEMA (2009). "FEMA benefit-cost analysis :Re-engineering (BCAR) hurricane wind module methodology report," in Federal Emergency Management Agency $y$ National Institute of Building Sciences (Washington, DC: FEMA).

\section{DATA AVAILABILITY STATEMENT}

All datasets generated for this study are included in the article/supplementary material, further inquiries can be directed to the corresponding author.

\section{AUTHOR CONTRIBUTIONS}

CF initiated and supervised this research. FO developed the modeling and decision making framework. FO and CF contributed the organizing the research, formulation, and selection and evaluation of the case study as well as writing of the manuscript. Both authors contributed to the article and approved the submitted version.

\section{ACKNOWLEDGMENTS}

The authors gratefully acknowledge funding from FEMA Grant Number 1603-DR-LA, Project 0039 Statewide Hazard Mitigation Community Education and Outreach Project, CFDA \# 97-039 through the Louisiana Governor's Office of Homeland Security and Emergency Preparedness (GOHSEP) "Get a Game Plan” Program as a subrecipient through the LSU AgCenter. Additionally, the authors acknowledge the contributions of Dr. Robert V. Rohli, who provided feedback on the article. Publication of this article was subsidized by the LSU Libraries Open Access Author Fund.

FEMA (2012). HAZUS MH MR2 Multi-Hazard Loss Estimation Methodology: Hurricane Model Technical Manual. Washington, DC: FEMA.

Fuchs, S., Thöni, M., McAlpin, M. C., Gruber, U., and Bründl, M. (2007). Avalanche hazard mitigation strategies assessed by cost effectiveness analyses and cost benefit analyses-evidence from Davos, Switzerland. Nat. Hazards 41, 113-129. doi: 10.1007/s11069-006-9031-z

Godschalk, D. R., Rose, A., Mittler, E., Porter, K., and West, C. T. (2009). Estimating the value of foresight: aggregate analysis of natural hazard mitigation benefits and costs. J. Environ. Plann. Manag. 52, 739-756. doi: 10.1080/ 09640560903083715

Grossi, P., and Kunreuther, H. (2005). Catastrophe Modeling: A New Approach to Managing Risk. New York, NY: Springer. doi: 10.1007/b100669

Hamid, S. S., Pinelli, J.-P., Chen, S.-C., and Gurley, K. (2011). Catastrophe modelbased assessment of hurricane risk and estimates of potential insured losses for the state of Florida. Nat. Hazards Rev. 12, 171-176. doi: 10.1061/(ASCE)NH. 1527-6996.0000050

Heneka, P., and Ruck, B. (2008). A damage model for the assessment of storm damage to buildings. Eng. Struct. 30, 3603-3609. doi: 10.1016/j.engstruct.2008. 06.005

Huang, Z., Rosowsky, D. V., and Sparks, P. R. (2001). Hurricane simulation techniques for the evaluation of wind-speeds and expected insurance losses. J. Wind Eng. Ind. Aerodyn. 89, 605-617. doi: 10.1016/S0167-6105(01)00061-7

Jain, V. K., Davidson, R., and Rosowsky, D. (2005). Modeling changes in hurricane risk over time. Nat. Hazards Rev. 6, 88-96. doi: 10.1061/(ASCE)1527698820056:2(88)

Khanduri, A. C., and Morrow, G. C. (2003). Vulnerability of buildings to windstorms and insurance loss estimation. J. Wind Eng. Ind. Aerodyn. 91, 455-467. doi: 10.1016/S0167-6105(02)00408-7

Legg, M. R., Nozick, L. K., and Davidson, R. A. (2010). Optimizing the selection of hazard-consistent probabilistic scenarios for long-term regional hurricane loss estimation. Struct. Saf. 32, 90-100. doi: 10.1016/j.strusafe.2009.08.002 
Li, Y. (2010). Assessment of damage risks to residential buildings and costbenefit of mitigation strategies considering hurricane and earthquake hazards. J. Perform. Constr. Facil. 26, 7-16.

$\mathrm{Li}$, Y. (2012). Assessment of damage risks to residential buildings and costbenefit of mitigation strategies considering hurricane and earthquake hazards. J. Perform. Construct. Facil. 26, 7-16. doi: 10.1061/(ASCE)CF.1943-5509. 0000204

Li, Y., and Ellingwood, B. R. (2006). Hurricane damage to residential construction in the US: importance of uncertainty modeling in risk assessment. Eng. Struct. 28, 1009-1018. doi: 10.1016/j.engstruct.2005.11.005

MMC (2017). Natural Hazard Mitigation Saves: 2017 Interim Report. Washington, DC: National Institute of Building Sciences.

Noori, M., Miller, R., Kirchain, R., and Gregory, J. (2018). How much should be invested in hazard mitigation? Development of a streamlined hazard mitigation cost assessment framework. Int. J. Disaster Risk Reduct. 28, 578-584. doi: 10.1016/j.ijdrr.2018.01.007

Orooji, F., and Friedland, C. J. (2017). Cost-benefit framework to generate wind hazard mitigation recommendations for homeowners. J. Arch. Eng. 23:04017019. doi: 10.1061/(ASCE)AE.1943-5568.000 0269

Orooji, F., and Friedland, C. J. (2020). Average annual wind loss libraries to support resilient housing and community decision-making. Hous. Soc. doi: 10.1080/ 08882746.2020.1796108

Pan, Q. (2011). Economic losses from a hypothetical hurricane event in the Houston-Galveston area. Nat. Hazards Rev. 12, 146-155. doi: 10.1061/(ASCE) NH.1527-6996.0000036

Peacock, W. G. (2003). Hurricane mitigation status and factors influencing mitigation status among Florida’s single-family homeowners. Nat. Hazards Rev. 4, 149-158. doi: 10.1061/(ASCE)1527-698820034:3(149)

Pinelli, J.-P., Gurley, K. R., Subramanian, C. S., Hamid, S. S., and Pita, G. L. (2008). Validation of a probabilistic model for hurricane insurance loss projections in Florida. Reliabil. Eng. Syst. Saf. 93, 1896-1905. doi: 10.1016/j.ress.2008. 03.017

Pinelli, J.-P., Simiu, E., Gurley, K., Subramanian, C., Zhang, L., Cope, A., et al. (2004). Hurricane damage prediction model for residential structures. J. Struct. Eng. 130, 1685-1691. doi: 10.1061/(ASCE)0733-9445(2004)130:11(1685)

Pinelli, J.-P., Torkian, B. B., Gurley, K., Subramanian, C., and Hamid, S. (2009). "Cost effectiveness of hurricane mitigation measures for residential buildings," in Proceedings, 11th America's Conference on Wind Engineering, American Association of Wind Engineering, Heathrow.
Pita, G. L., Pinelli, J.-P., Gurley, K. R., and Hamid, S. (2013). Hurricane vulnerability modeling: development and future trends. J. Wind Eng. Ind. Aerodyn. 114, 96-105. doi: 10.1016/j.jweia.2012.12.004

Rose, A., Porter, K., Dash, N., Bouabid, J., Huyck, C., Whitehead, J., et al. (2007). Benefit-cost analysis of FEMA hazard mitigation grants. Nat. Hazards Rev. 8, 97-111. doi: 10.1061/(ASCE)1527-698820078:4(97)

Rosowsky, D. V., and Ellingwood, B. R. (2002). Performance-based engineering of wood frame housing: fragility analysis methodology. J. Struct. Eng. 128, 32-38. doi: 10.1061/(ASCE)0733-94452002128:1(32)

RSMeans (2013). RSMeans Residential Cost Data, 2013. Rockland, MA: RS Means Company.

Shreve, C. M., and Kelman, I. (2014). Does mitigation save? Reviewing costbenefit analyses of disaster risk reduction. Int. J. Disaster Risk Reduc. 10(Part A), 213-235. doi: 10.1016/j.ijdrr.2014.08.004

Smyth, A. W., Altay, G., Deodatis, G., Erdik, M., Franco, G., Gülkan, P., et al. (2004). Probabilistic benefit-cost analysis for earthquake damage mitigation: evaluating measures for apartment houses in Turkey. Earthquake Spectra 20, 171-203. doi: 10.1193/1.1649937

Torkian, B. B., Pinelli, J.-P., Gurley, K., and Hamid, S. (2013). Cost and benefit evaluation of windstorm damage mitigation techniques in Florida. Nat. Hazards Rev. 15, 150-157. doi: 10.1061/(ASCE)NH.1527-6996.0000122

Valcárcel, J. A., Mora, M. G., Cardona, O. D., Pujades, L. G., Barbat, A. H., and Bernal, G. A. (2013). Methodology and applications for the benefit cost analysis of the seismic risk reduction in building portfolios at broadscale. Nat. Hazards 69, 845-868. doi: 10.1007/s11069-013-0739-2

Vickery, P. J., Skerlj, P. F., Lin, J., Twisdale, L. A. Jr., Young, M. A., and Lavelle, F. M. (2006). HAZUS-MH hurricane model methodology. II: damage and loss estimation. Nat. Hazards Rev. 7, 94-103. doi: 10.1061/(ASCE)1527-6988(2006) $7: 2(94)$

Conflict of Interest: The authors declare that the research was conducted in the absence of any commercial or financial relationships that could be construed as a potential conflict of interest.

Copyright (C) 2021 Orooji and Friedland. This is an open-access article distributed under the terms of the Creative Commons Attribution License (CC BY). The use, distribution or reproduction in other forums is permitted, provided the original author(s) and the copyright owner(s) are credited and that the original publication in this journal is cited, in accordance with accepted academic practice. No use, distribution or reproduction is permitted which does not comply with these terms. 